Jurnal Teknik Hidro

Vol. 12 No. 1, Februari 2019

\title{
STUDI PENGARUH BANGUNAN CONSOLIDATION DAM CD 1-1 TERHADAP LAJU SEDIMENTASI DI SUNGAI JENEBERANG
}

\author{
Muhammad Syafa'at S. Kuba ${ }^{1)}$ Irma Suryana $^{2)}$ Dan Lisnawati ${ }^{3)}$ \\ 1)Universitas Muhammadiyah Makassar, Indonesia \\ Email:syafaat_skuba@rocketmail.com \\ ${ }^{2)}$ Universitas Muhammadiyah Makassar, Indonesia \\ Email:irmasuryana99@gmail.com \\ ${ }^{3)}$ Universitas Muhammadiyah Makassar, Indonesia \\ Email:lisnawati.sabar@gmail.com
}

\begin{abstract}
Abstrak
Penelitian ini bertujuan untuk mengetahui pengaruh bangunan Consolidation Dam CD 1-1 terhadap laju sedimentasi dan volume tampungan pada bangunan Consolidation Dam CD 1-1. Pada hasil perhitungan laju sedimen menggunakan analisis berdasarkan Suripin dan perhitungan volume tampungan menggunakan perhitungan volume ruang dengan rumus prisma segitiga. Debit sedimen harian menurut Suripin dengan konsentrasi sedimen $\left(C_{s}\right)=1,9 \times 10^{-7}$ ton, debit sedimen harian $=0,25$ ton $/ \mathrm{jam}$, dan 0,0864 untuk konversi satuan dari $\mathrm{kg} / \mathrm{sek} \mathrm{ke}$ ton/tahun. Untuk perhitungan laju sedimen 0,2145 ton/tahun. Volume tampungan sedimen pada bangunan Consolidation Dam CD 1 $1=99.246 \mathrm{~m}^{3}$. Berdasarkan hasil perhitungan menunjukkan kondisi bangunan saat ini masih aman dalam jumlah volume tampungan sedimen.
\end{abstract}

Kata Kunci: Sedimentasi, Dam Sabo, Sungai Jeneberang

\begin{abstract}
This study aims to determine the effect of building Consolidation Dam CD 1-1 on the sedimentation rate and the volume of the container in the building Consolidation Dam CD 1-1. In the calculation result of sediment rate using analysis based on Suripin and calculation of storage volume using space volume calculation with triangular prism formula. Daily sediment discharge according to Suripin with sediment concentration (Cs) $=1.9 \times 10-7$ tons, daily sediment discharge $=0.25$ tons $/$ hour, and 0.0864 for unit conversion from $\mathrm{kg} / \mathrm{sek}$ to ton / year. For the calculation of sediment rate 0.2145 ton / year. Sedimentary sediment volume in Building Consolidation Dam CD 1-1 =99.246 m3. Based on the calculation shows the current condition of the building is still safe in the amount of sediment storage volume.
\end{abstract}

Keywords: Sedimentation, Dam Sabo, Jeneberang River

\section{PENDAHULUAN}

Air yang bercampur dengan material padat berupa pasir dan batu-batu besar dalam konsentrasi sangat tinggi, bergerak bersama dengan cepat menuruni lereng gunung atau alur sungai memiliki kekuatan daya rusak yang besar, sehingga menimbulkan ancaman bencana sepanjang pengalirannya dari hulu ke hilir. 
Curah hujan dalam waktu lama dengan intensitas tinggi, serta longsor yang terjadi didaerah pegunungan dapat menyebabkan material pengunungan mengalir menuju sungai. Kecepatan dan volume material yang besar bersifat merusak terhadap apapun yang dilalui aliran tersebut.

Banjir dan longsor merupakan permasalahan yang paling dominan di daerah hulu.

\section{Sungai}

Suatu alur yang panjang di atas permukaan bumi tempat mengalirnya air yang berasal dari hujan disebut alur sungai. Bagian yang senantiasa tersentuh aliran air ini disebut alur sungai. Dan perpaduan antara alur sungai dan aliran air di dalamnya disebut sungai.

Kadang-kadang sungai yang bermuara di sebuah danau atau di pantai laut terdiri dari beberapa cabang, maka sungai yang paling penting, yakni sungai utama (main river), sedangkan cabang-cabang lainnya disebut anak sungai (tributary). Kadang-kadang sebelum alirannya berakhir di sebuah danau atau pantai laut, sungai membentuk beberapa buah cabang yang disebut cabang sungai (enffluent).

Lokasi anak sungai dalam suatu daerah pengaliran terutama ditentukan oleh keadaan daerahnya. Sungai A pada Gambar 1 mempunyai dua anak sungai yang mengalir bersama-sama dan bertemu setelah mendekati muara yang disebut sungai tipe sejajar. Sebaliknya ada pula sungai-sungai yang anak-anak sungainya mengalir menuju suatu titik pusat (sungai B pada Gambar 1) yang disebut tipe kipas.Ada juga tipe-tipe lainnya seperti tipe cabang pohon (sungai $\mathrm{C}$ pada Gambar 1) yang mempunyai beberapa anak sungai yang mengalir ke sungai utama di kedua sisinya pada jarak-jarak tertentu.

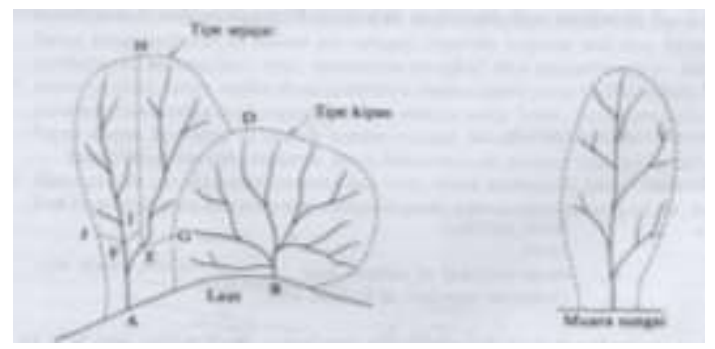

Gambar 1. Daerah pengaliran sungai dan pola susunan anak-anak sungainya. (Sumber : Perbaikan dan Pengaturan Sungai, Suyono Sudarsono dan Masateru Tominaga, 2008)

\section{Erosi}


Erosi adalah pemindahan dan Fungsi utama Dam Pengendali transportasi material permukaan Bumi Sedimen atau Dam Sabo adalah :

yang kebanyakan berupa tanah dan debris batuan (regolith), bahan-bahan yang tererosi secara alami.

Secara umum, terjadinya erosi

1) Memperlandai kemiringan dasar sungai, menurangi kecepatan aliran dan mencegah terjadinya ditentukan oleh faktor-faktor iklim (terutama intensitas hujan), topografi, karakteristik tanah, vegetasi penutup tanah, dan tata guna lahan. Proses erosi terdiri atas tiga bagian yang berurutan: pengelupasan (detachment), pengangkutan (transportation), dan pengendapan (sedimentation).

\section{Sedimen}

Sedimen adalah hasil proses erosi, baik berupa erosi permukaan, erosi parit, atau jenis erosi tanah lainnya. Sedimen umumnya mengendap di bagian bawah kaki bukit, di daerah genangan banjir, di saluran air, sungai, dan waduk.

Sedimentasi adalah suatu proses pengendapan material.

\section{Bangunan Pengendali Sedimen}

Dam Pengendali Sedimen (Dam Sabo) merupakan salah satu dari beberapa struktur bangunan pengendali sedimen yang mempunyai peranan paling dominan dalam mengendalikan sedimen. erosi vertikal

2) Mengatur arah aliran untuk mencegah terjadinya erosi lateral

3) Menstabilkan kaki bukit untuk mencegah longsoran lereng bukit

4) Menahan dan mengendalikan sedimen yang mengalir ke arah hilir dengan mereduksi debit puncak

Tipikal Dam Sabo terdiri dari tubuh dam utama (main dam) sebagai struktur utama (main structures) yang berfungsi menahan, mengontrol dan menampung sedimen dan struktur pendukung (supporting structures) yang merupakan struktur bagian depan bangunan, berfungsi mengamankan keberadaan struktur utama yaitu tubuh dam utama.

Selain fungsi utama bangunan, seringkali keberadaan bangunan pengendali sedimen dapat memberikan manfaat tambahan, atau bahkan sengaja dibuat untuk dapat memberikan manfaat tambahan bagi masyarakat. Dipandang dari aspek 
operasi atau eksploitasi bangunan pengendali sedimen, manfaat tambahan tersebut dapat memberikan pengaruh positif terhadap bangunan dalam menjalankan fungsi utamanya, sepanjang persyaratan teknis untuk keamanan bangunan dipenuhi.

Beberapa manfaat tambahan bangunan pengendali sedimen yang dapat dieksploitasi, antara lain:

1) Pemanfaatan tampungan pasir di sebelah hulu dam pengendali sedimen atau bangunan lainnya untuk bahan galian golongan $\mathrm{C}$, dapat memberikan konstribusi positif terhadap penyediaan kembali kapasitas tampung bangunan untuk banjir yang akan datang

2) Pemanfaatan air sungai yang diambil di bangunan pengendali sedimen untuk berbagai keperluan, seperti irigasi, pembangkit listrik tenaga air berskala kecil (mini hydro power) dan sebagainya

3) Pemanfaatan dam pengendali sedimen untuk jembatan pelintas

4) Pemanfaatan sumber daya atau operasi bangunan yang dilakukan sesuai ketentuan teknis akan memberikan kontribusi positif terhadap bangunan.

\section{Dampak Negatif Pembangunan Sabo}

Hampir mustahil melakukan kegiatan pembangunan tanpa sedikitpun dampak negatif, terkhususnya mempengaruhi lingkungan. Meskipun sistem sabo tujuannya adalah memperbaiki kerusakan alur sungai dan sekitarnya.

Dampak negatif penerapan sistem sabo yang dapat terjadi terhadap lingkungan antara lain:

1) Kekhawatiran terhadap degradasi dasar sungai di hilirnya, yang dapat mempengaruhi pada kerusakan pilar jembatan dan dasar revetment, kesulitan pengambilan air pada bangunan intake irigasi akibat muka air turun

2) Kekhawatiran akumulasi deposit sementara di bagian hulu, yaitu: genangan atau banjir areal endapan, perubahan erosi lateral pada tanggul

3) Kekhawatiran terhadap menurunnya kwalitas biologi, seperti: Pengaruh terhadap 
perikanan darat, pengaruh terhadap penghutanan kembali atau reforestation dan kerusakan lahan dan panorama pemandangan

\section{Perhitungan Laju Sedimentasi}

Untuk mendapatkan jumlah sedimen yang lewat pada suatu periode tertentu (Sediment rate), maka dilakukan metode dengan menggunakan persamaan sebagai berikut : Metode hubungan debit air $\left(\mathrm{Q}_{\mathrm{w}}\right)$ dengan debit sedimen $\left(\mathrm{Q}_{\mathrm{s}}\right)$. Dimana harga $\mathrm{Q}_{\mathrm{s}}$ dapat diperoleh setelah didapat konsentrasi sedimen $\left(\mathrm{C}_{\mathrm{s}}\right)$ dari hasil contoh sedimen dilapangan yang dianalisa di laboratorium.

Perhitungan besarnya debit sedimen harian menurut Suripin, 2002 dihitung dengan rumus :

$\mathrm{Q}_{\mathrm{s}}=0.0864 \mathrm{C}_{\mathrm{s}} \mathrm{Q}_{\mathrm{w}}$

Dimana:

$\mathrm{Q}_{\mathrm{s}}=$ Debit sedimen harian (ton/hari)

$\mathrm{Q}_{\mathrm{w}}=$ Debit aliran harian $\left(\mathrm{m}^{3} / \mathrm{det}\right)$

$\mathrm{C}_{\mathrm{s}}=$ Konsentrasi sedimen layang $(\mathrm{mg} / \mathrm{l})$

$0.0864=$ Konversi satuan dari $\mathrm{kg} / \mathrm{sek}$ ke ton/hari

$=24 \times 30 \times 30$ (ton/hari) dikalikan dengan 30 hari untuk ton/bulan

Konsentrasi sedimen $\left(\mathrm{C}_{\mathrm{s}}\right)$ adalah banyaknya sedimen ynag tersuspensi dalam volume air tertentu. Pengukuran dilakukan dengan cara mengambil sampel/contoh air dan membawa ke laboratorium untuk dapat diketahui konsentrasi sedimen dalam $\mathrm{mg} / \mathrm{liter}$. (Supangat, 2014)

\section{METODE PENELITIAN}

\section{Tempat danWaktu Penelitian}

Penelitian dilaksanakan di bagian hulu Sungai Jeneberang tepatnya pada bangunan Consolidation DAM CD 1-1 Sungai Jeneberang dengan rencana waktu penelitian selama 6 bulan.

\section{Bahan dan Alat Penelitian}

Bahan penelitian terdiri dari:

1) Buku dan jurnal yang menunjang penelitian ini

2) Data-data sekunder dan primer berupa:

a) Peta topografi

b) Data sedimen Kaldera Bawakaraeng

c) Data bangunan Consolidation CD.1-1

d) Data debit aliran

\section{Alat-Alat yang Digunakan}

1) Bola Pimpong

2) Botol air tembus pandang

3) Tongkat penggantung

4) Alat ukur waktu (stopwacth) 


\section{Jurnal Teknik Hidro}

\section{Vol. 12 No. 1, Februari 2019}

5) Alat ukur panjang (meteran)

Untuk perhitungan Konsentrasi

6) Kertas dan alat tulis untuk Sedimen $\left(C_{s 1}\right)$ rumus yang digunakan mencatat data-data yang adalah sebagai berikut: diperlukan.

7) Kamera digital digunakan untuk dokumentasi.

8) Komputer, printer dan scanner digunakan untuk membantu dalam menganalisa data.

\section{BaganAlurPenelitian}

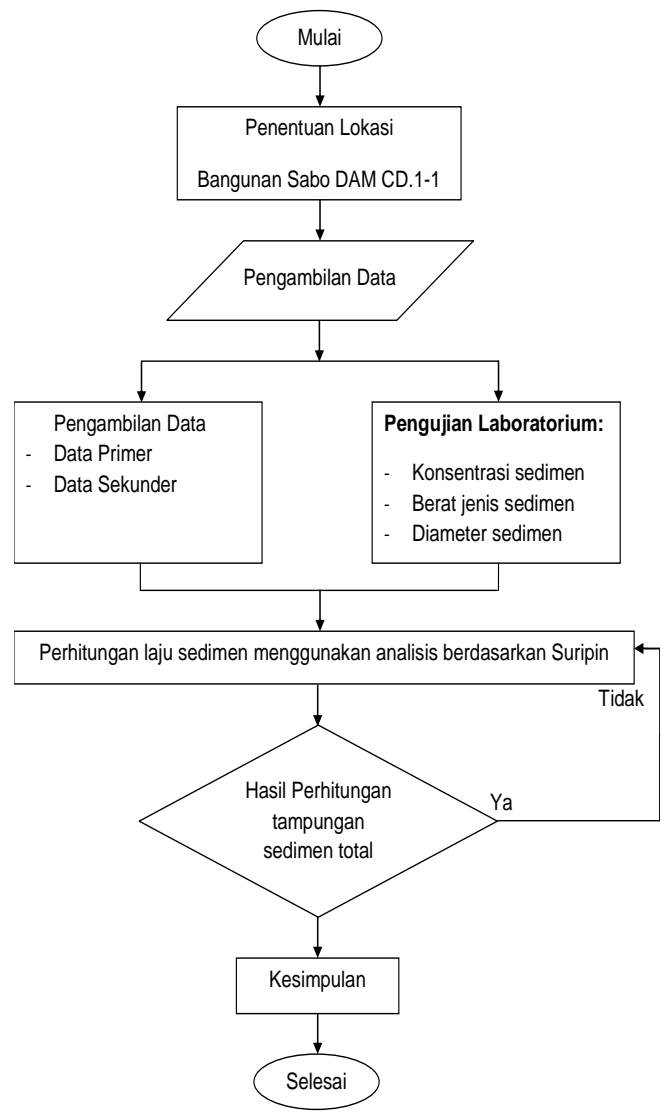

Gambar 2. Gambar Flow Chart

Penelitian

HASIL DAN PEMBAHASAN

Perhitungan Konsentrasi Sedimen

$$
C_{s}=\frac{W_{s}}{W_{\text {total }}}
$$

$\operatorname{Untuk}_{s} 1=\frac{1 \mathrm{gram}}{6 \mathrm{gram}}$

$$
=0,17 \text { gram }
$$

$U n t u k C_{s} 2=\frac{2 \mathrm{gram}}{9 \mathrm{gram}}$

$$
=0,22 \text { gram }
$$

Jadi, $C_{s}=\frac{0,17+0,22}{2}=0,19 \mathrm{gram}$

Tabel 1. Hasil Perhitungan Konsentrasi Sedimen

\begin{tabular}{clcc}
\hline No. & \multicolumn{1}{c}{ Keterangan } & $\begin{array}{c}\text { I } \\
\text { (gram) }\end{array}$ & II (gram) \\
\hline 1 & Berat sampel basah & 100 & 100 \\
\hline 2 & $\begin{array}{l}\text { Berat sampel kering } \\
\text { (sebelum dicuci) }\end{array}$ & 95 & 93 \\
\hline 3 & Berat air (1-2) & 5 & 7 \\
\hline 4 & $\begin{array}{l}\text { Berat sampel setelah } \\
\text { dicuci }\end{array}$ & 94 & 91 \\
\hline 5 & $\begin{array}{l}\text { Berat kadar lumpur } \\
(2-4)\end{array}$ & 1 & 2 \\
\hline 6 & $\quad C_{s}=\frac{W_{s}}{W_{\text {total }}}$ & & 0,17 \\
\hline$\quad$ Konsentrasi sedimen & 0,19 \\
\hline & Rata-rata & \multicolumn{2}{c}{0,19} \\
\hline
\end{tabular}

\section{Perhitungan Berat Jenis Sedimen}

Untuk perhitungan Berat Jenis

Sedimen $\left(\mathrm{G}_{\mathrm{s}}\right)$ rumus yang digunakan adalah sebagai berikut:

Untuk $G_{S} 1=\frac{\alpha \cdot W_{S}}{\left(W_{2}+W_{s}-W_{3}\right)}$

$$
\begin{aligned}
& =\frac{0,99267 \times 25}{(142,1+25-158,2)} \\
& =2,79
\end{aligned}
$$

Untuk $G_{s} 2=\frac{\alpha \cdot W_{S}}{\left(W_{2}+W_{s}-W_{3}\right)}$ 


$$
\begin{aligned}
& =\frac{0,99267 \times 25}{(144,2+25-159,2)} \\
& =2,59
\end{aligned}
$$

Jadi, $G_{S}=\frac{2,79+2,59}{2}=2,69$

Tabel 2. Hasil Pengujian Berat Jenis

\begin{tabular}{|c|c|c|}
\hline Nomor Percobaan & $\mathrm{I}$ & II \\
\hline $\begin{array}{l}\text { Berat Piknometer, } \\
W_{1} \text { (gram) }\end{array}$ & 45 & 46 \\
\hline $\begin{array}{l}\text { Berat Piknometer + air, } \\
W_{2}(\text { gram })\end{array}$ & 142,1 & 144,2 \\
\hline $\begin{array}{l}\text { Berat Piknometer + air + } \\
\text { tanah, } W_{3}(\text { gram })\end{array}$ & 158,2 & 159,6 \\
\hline $\begin{array}{l}\text { Berat tanah kering, } \\
\mathrm{W}_{\mathrm{s}}(\mathrm{gram})\end{array}$ & 25 & 25 \\
\hline Temperatur, ${ }^{\circ} \mathrm{C}$ & 28 & 28 \\
\hline Faktor koreksi, $\alpha$ & 0,99267 & 0,99267 \\
\hline Berat Jenis, Gs & 2,79 & 2,59 \\
\hline Berat Jenis Rata-rata, Gs & & \\
\hline
\end{tabular}

Sedimen

\section{Perhitungan Diameter Sedimen}

Penentuan diameter sedimen dalam hal ini adalah melalui percobaan analisa saringan yang dilakukan di laboratorium, sehingga dari hasil percobaan tersebut dapat kita peroleh nilai diameter butiran atau koefisien gradasi dari sedimen tersebut. Adapun nilai diameter yang seragam $\left(\mathrm{d}_{50}\right)$ yang diperoleh yaitu $=0,5089 \mathrm{~mm}$.

Tabel 3. Hasil Pengujian Analisa Saringan

\begin{tabular}{cccccc}
\hline $\begin{array}{c}\text { Saringan } \\
\text { No. }\end{array}$ & $\begin{array}{c}\text { Diameter } \\
\text { (mm) }\end{array}$ & $\begin{array}{c}\text { Berat } \\
\text { Tertahan } \\
\text { (gram) }\end{array}$ & $\begin{array}{c}\text { Berat } \\
\text { Kumulatif } \\
\text { (gram) }\end{array}$ & \multicolumn{2}{c}{ Persen (\%) } \\
Tertahan & Lolos \\
\hline \hline 4 & 4,75 & 0 & 0 & 0 & 100 \\
\hline 10 & 2 & 38 & 38 & 7,6 & 92,4 \\
\hline 18 & 0,84 & 70 & 108 & 21,6 & 78,4 \\
\hline 40 & 0,425 & 178 & 286 & 57,2 & 42,8 \\
\hline 60 & 0,25 & 175 & 461 & 92,2 & 7,8 \\
\hline 100 & 0,15 & 31 & 492 & 98,4 & 1,6 \\
\hline 200 & 0,075 & 8 & 500 & 100 & 0 \\
\hline Pan & - & 0 & 500 & 100 & 0 \\
\hline
\end{tabular}

\section{Menghitung D50}

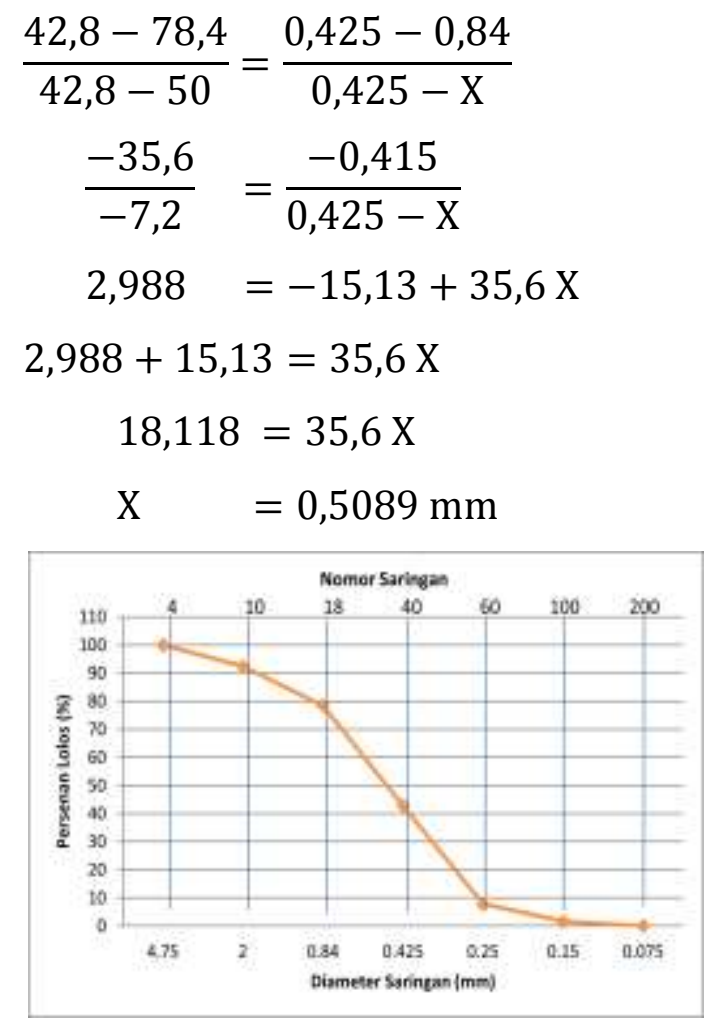

Gambar 3. Grafik Analisa Saringan

Berdasarkan diameter sedimen diatas, maka sedimen ini dapat diklarifikasikan sebagai sedimen dengan jenis sedang (medium sand) karena ukurannya yang berada di antara 0,2 $\mathrm{mm}$ sampai $0,6 \mathrm{~mm}$.

\section{Perhitungan Debit Sedimen}

Pada pengujian perhitungan debit sedimen, dilakukan pengukuran langsung pada lokasi penelitian dengan menggunakan Metode Apung, berupa pengukuran luas penampang dan kecepatan aliran pada sungai tersebut.

\section{Perhitungan Luas Penampang (A)}


Tabel 4. Penghitungan Luas Penampang

(A)

\begin{tabular}{lcccc}
\hline \multirow{2}{*}{ Titik } & $\begin{array}{c}\text { Lebar } \\
(\mathrm{L})\end{array}$ & \multicolumn{4}{c}{$\begin{array}{c}\text { Kedalaman }(\mathrm{H}) \\
(\text { Meter })\end{array}$} \\
\cline { 3 - 5 } & $($ Meter $)$ & $\mathrm{H}_{1}$ & $\mathrm{H}_{2}$ & $\mathrm{H}_{3}$ \\
\hline Titik 1 & $67,65 \mathrm{~m}$ & 0,67 & 0,75 & 0,63 \\
\hline Titik 2 & 48,40 & 0,23 & 0,45 & 0,56 \\
\hline Titik 3 & 54,96 & 0,36 & 0,42 & 0,39 \\
\hline Jumlah & 171,01 & $\begin{array}{l}\text { Jumlah Kedalaman } \\
(\mathrm{H})\end{array}$ & 4,46 \\
\hline Rata- & 57,003 & $\begin{array}{l}\text { Rata-Rata } \\
\text { Rata }\end{array}$ & \multicolumn{4}{l}{ Kedalaman (H) } & 0,49 \\
\hline
\end{tabular}

Luas penampang (A) merupakan hasil perkalian antara lebar rata-rata (L) saluran/ aliran dengan kedalaman ratarata $(\mathrm{H})$ saluran/ aliran.

$$
\begin{aligned}
A & =L_{\text {rata-rata }} \times H_{\text {rata-rata }} \\
A & =57,003 \times 0,49 \\
A & =27,93 \mathrm{~m}
\end{aligned}
$$

\section{Perhitungan Kecepatan (V)}

Panjang saluran/lintasan pengukuran $(\mathrm{P})=50$ meter $($ panjang lintasan harus tetap)

Tabel 5. Perhitungan Kecepatan

\begin{tabular}{lc}
\hline Pengulangan & Waktu Pengukuran $(\mathrm{T})$ (detik) \\
\hline Pengukuran 1 & 14,70 \\
\hline Pengukuran 2 & 24,35 \\
\hline Pengukuran 3 & 29,93 \\
\hline Jumlah & 68,98 \\
\hline Rata-rata & 22,99 \\
\hline
\end{tabular}

Kecepatan (v) adalah hasil pembagian antara panjang saluran/aliran dibagi dengan waktu rata-rata ( $\mathrm{T}$ ratarata).

$V=\frac{P}{T_{\text {rata-rata }}}$

$V=\frac{50}{22,99}$

$V=2,17 \mathrm{~m} /$ detik

\section{Perhitungan Debit Air}

Debit air (Q) merupakan hasil perkalian antara luas penampang (A) saluran/aliran dengan kecepatan (V) aliran air.

$Q=A \times V$

$Q=27,93 \times 2,17$

$Q=60,61 \mathrm{~m}^{3} / \mathrm{dt}$

\section{Perhitungan Laju Sedimentasi}

\section{berdasarkan Persamaan}

Perhitungan besarnya debit sedimen harian menurut Suripin (2002, terlampir) dihitung dengan rumus :

$$
\begin{aligned}
\mathrm{Q}_{\mathrm{s}=} & 0.0864 \mathrm{C}_{\mathrm{s}} \mathrm{Q}_{\mathrm{w}} \\
\mathrm{Q}_{\mathrm{sm}} & =0.0864 \times \mathrm{C}_{\mathrm{s}} \times \mathrm{Q}_{\mathrm{w}} \\
& =0.0864 \times\left(1,9 \times 10^{-7}\right) \times 0,25 \\
& =4,13 \times 10^{-9} \times 24 \times 60 \times 60 \times 365 \\
& =0,13 \text { ton } / \text { tahun } \\
\mathrm{Q}_{\mathrm{sd}} & =65 \% \times 0,13 \\
& =0,0845 \text { ton } / \text { tahun }
\end{aligned}
$$

$$
\begin{aligned}
\mathrm{Q}_{\text {,total }} & =0,13+0,0845 \\
& =0,2145^{\text {ton }} / \text { tahun }
\end{aligned}
$$


Jurnal Teknik Hidro

Vol. 12 No. 1, Februari 2019

\section{Perhitungan Volume Tampungan}

Berdasarkan data, BBWS Pompengan Jeneberang menghitung volume tampungan Sabo DAM berdasarkan garis kontur, dimulai dari garis kontur paling bawah pada bangunan Consolidation DAM CD.1-1 +.EL 539,282 sampai kontur teratas pada bangunan Consolidation DAM CD.2 +.EL 697,000 yang menjadi tampungan air pada kondisi normal maupun banjir. Dengan garis kontur yang berupa poligon tertutup, dengan software Cad dapat dihitung luasnya. Bila ada pulau atau gundukan maka luasnya dikurangi dengan luas dari kontur yang elevasinya sama dari pulau atau gundukan tersebut. Berdasar daftar elevasi dan luas dapat dihitung volume ruang dengan rumus prisma segitigasebagai berikut.

$L A=1 / 2 \times a \times t$

$L A=1 / 2 \times 116,76 \times 5$

$L A=291,9 \mathrm{~m}^{2}$

Dan untuk volume tampungan sedimen pada bangunan Consolidation DAM CD 1-1 adalah:

$$
\begin{aligned}
& V=L A \times T_{\text {prisma }} \\
& V=291,9 \times 340 \\
& V=99.246 \mathrm{~m}^{3}
\end{aligned}
$$

Jadi, untuk kapasitas volume tampungan sedimen pada bangunan Consolidation DAM CD 1-1 adalah $99.246 \mathrm{~m}^{3}$.

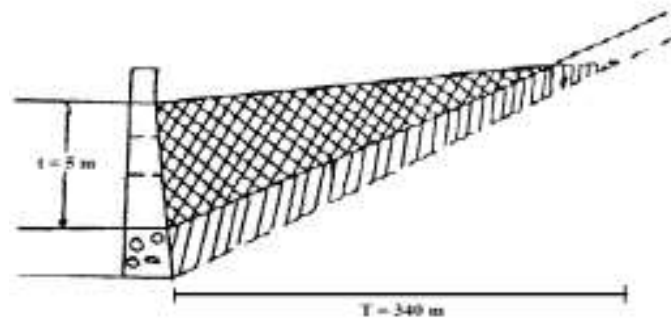

Gambar 4. Sketsa Volume Tampungan Pada Bangunan Consolidation DAM CD 1-1

\section{PENUTUP}

\section{Kesimpulan}

Berdasarkan hasil dan pembahasan pada bab sebelumnya, maka dapat ditarik kesimpulan bahwa :

1) Perhitungan laju sedimentasi menggunakan metode Suripin pada bangunan Consolidation Dam CD 1-1 di Sungai Jeneberang, kecepatan peningkatan sedimennya masih tinggi walaupun sudah ada beberapa bangunan sebelum bangunan Consolidation Dam CD 1-1.

2) Dari hasil perhitungan volume tampungan sedimentasi pada bangunan Consolidation Dam CD 
1-1 ini masih dalam kondisi aman dengan persentase $15 \%$.

\section{Saran}

1) Kondisi bangunan Consolidation DAM CD 1-1 saat ini masih aman dalam hal jumlah sedimen yang tertampung, akan tetapi berdasarkan analisa perhitungan volume sedimen dalam periode bangunan 1 tahun maka diperlukan penambahan bangunan

Consolidation DAM.

2) Perlu adanya pengamatan serta pengukuran debit, pengukuran sedimentasi dan kecepatan aliran yang berkelanjutan, untuk mendapatkan data-data yang akurat.

3) Perlu adanya penelitian selanjutnya untuk menghitung periode tampungan 10 tahun kemudian dan jumlah total laju sedimentasi di hulu.

4) Untuk Perpustakaan Jurusan Sipil dan Perpustakaan Umum Universitas Muhammadiyah Makassar sebaiknya menyiapkan dan melengkapi buku-buku sipil tentang sedimen untuk menunjang proses belajar mengajar dan penyusunan tugas akhir.

\section{DAFTAR PUSTAKA}

Ahmad, dkk., 2011. Dampak Longsoran Kaldera Terhadap Tingkat Sedimentasi Di Waduk Bili-Bili Provinsi Sulawesi Selatan, Jurnal Teknik Sipil Universitas Institut Pertanian Bogor.

Arham. Nasti, A. Ismail., 2016. Pengaruh Kecepatan Aliran Terhadap Volume Angkutan Sedimen Dasar Pada Saluran Terbuka Dengan Pendekatan Empiris, Jurnal Teknik Sipil Universitas Muhammadiyah Makassar.

Asdak, Chay. 2010. Hidrologi dan Pengelolaan Daerah Aliran Sungai. Gajah Mada University Press. Yogyakarta.

Belle, Resnie., 2014. Analisis Perhitungan Muatan Sedimen (Bed Load) Pada Muara Sungai Lilin Kabupaten Musi Banyuasin, Jurnal Teknik Sipil Universitas Sriwijaya.

Dunne, T., dan Leopold, L. B., 1978. Water in Environmetal Planing. W.H. Freeman and Company, San Fransisco.

HR, Nur Khuzaimah., 2013. Studi Penyebaran Sedimen Muara Sungai Jeneberang, Jurnal Teknik Sipil Universitas Hasanuddin.

Ismanto, Ardi., 2012. Pengukuran Debit Air Secara Sederhana. Konservasi Alam- BBKSDA. 
Kusumosubroto, Haryono., 2012. Desain Bangunan Pengendali Sedimen. Pemutakhiran Buku Teknologi Sabo, Kementrian PU, Jakarta.

Kusumosubroto, Haryono., 2012. Implementasi Sabo, Kementrian PU, Jakarta.

Kusumosubroto, Haryono., 2012. Operasi \& Pemeliharaan Bangunan Pengendali Sedimen $(\mathrm{O} \& \mathrm{P})$, Kementrian PU, Jakarta.

Mokonio, Olviana., 2013. Analisis Sedimentasi Di Muara Sungai Saluwangko Di DesaTounelet Kecamatan Kakas, Jurnal Teknik Sipil Universitas Sam Ratulangi

Mulyanto, HR., 2008. Efek Konservasi dari Sistem SABO untuk Pengendalian Sedimentasi Waduk:Graha Ilmu, Yogyakarta.

Munir, abdul., 2015. Studi Karakteristik Angkutan Sedimen Dasar Pada Upstream Sungai Jeneberang, Jurnal Teknik Sipil Universitas Hasanuddin.

Riskiyanti, Siti., 2015. Studi Laju Sedimentasi Waduk Bili-Bili Pasca Pengembangan Bangunan Penahan Sedimen, Jurnal Teknik Sipil Universitas Hasanuddin.

Sari, Tati Eka. 2011. Kajian Sedimentasi Dengan Model Musle Pada Das Babon Propinsi Jawa Tengah, Jurnal Teknik Sipil Universitas Semarang.
Suripin. 2002. Pelestarian Sumber Daya Tanah dan Air. Yogyakarta: Penerbit Andi.

Supangat, Agung B., 2014. Perhitungan Sedimen.

Suyono. Tominaga, Masateru., 2008. Perbaikan dan Pengaturan Sungai: PT.Pradnya Paramita, Jakarta.

Syawal Fitra, Fahri., 2016. Studi Keandalan Tampungan Sedimen Sabo DAM Sehati Pulau Seram Maluku Tengah, Jurnal Teknik Sipil Universitas Hasanuddin. 